\title{
Framework and Research Progress of Generation Energy Integrated Transport System Planning Methods in China
}

\author{
Shengyu Wu, Bo Yuan, and Songxu Xin
}

\begin{abstract}
Energy issues are the focus of national attention, integrated transport system of energy for generation is key to modern "Energy Internet". In this paper, the planning methods framework of integrated transport system of energy for generation is discussed, on the basis of integrated transport system. The framework is divided into five modules, including transport demand forecast, comparison among modes of transport, transportation pattern construction, evaluation of social benefits and transport coordination evaluation. Under the framework proposed, an overview of the planning methods used in China is presented. Finally, research prospect of planning method for integrated transport system of energy for generation is pointed out.
\end{abstract}

Index Terms-Energy for generation, integrated transport system, planning method.

\section{INTRODUCTION}

In China, study on energy integrated transport system, originated from the study on coal and electricity transmission channel construction issues [1], [2], can be traced back to the mid-1980s. In about 2010, the scope of the energy integrated energy transport system was extended, its transportation objects are no longer coal only and coal electricity, but also hydropower, nuclear power and other renewable energies [3], the channels are also extended to railways, highways, waterways, pipelines, power transmission lines and others [4]. The concept of China's integrated transport system was introduced in the 1950s by the Soviet Union [5]. China issued a "national long-term integrated transport network plan" in 2007. Viewed from the development process, idea proposing and connotation extension of energy integrated transport system is thanks to the development of the integrated transport system.

In the promotion of energy production and consumption revolution, the "integration" trend between electrical power and various energies grows significantly in China. The impetuses mainly include (a) as the consumption proportion of electricity energy accounting for final energy keeps rising; processing, transfer and transportation modes of primary energies coexist more with each other; (b) adjustment of energy structure leads to the increase of energy substitute and dependence among various energy transport infrastructures; (c) China's new energy production bases and imported countries have many varieties of energies, so there is a need to

Manuscript received October 15, 2015; revised January 12, 2016.

The authors are with the Department of Energy Strategy and Planning, State Grid Energy Research Institute, Beijing, China (e-mail: wushengyu@sgeri.sgcc.com.cn, yuanbo@sgeri.sgcc.com.cn, xinsongxu@sgeri.sgcc.com.cn). make integrated production. In this trend, integrated transport system of energy for generation will become the core of energy integrated transport system, study of planning theory and top design methods is of vital importance.

The integration of electrical power and various energies has not yet been fully realized in the planning level. In practice, China has formed separate plans for coal, electricity, oil and gas, railways and others, and the formation of each special plan lacks coordination. In theoretical and methodological level, although there are related studies, but they lack comprehensive arrangement in the perspective of the overall framework. The research direction suitable for a more integrated development trend of future power and energy is not clear.

Compared with planning theory of rather mature integrated transport system, the planning theory of integrated transport system of energy for generation is not yet perfect. This paper, based on the reference of former, will join the discussion on building the planning method framework of the integrated energy transportation system of energy for generation. The framework takes size, structure and layout of the integrated transport system of energy for generation development as the main subject and includes phases from planning to evaluation. Under this framework, based on related domestic research progress, the status quo of China's planning methods for integrated transport system of energy for generation is presented. The paper is organized as follows, Section II is planning methods framework construction, Section III to Section VII are study overview on transportation demand forecasting, comparison of transportation ways, integrated system construction, social benefit evaluation and coordination evaluation respectively, and points out the main direction of future research and key issues that need to be addressed.

\section{THEORETICAL FRAMEWORK OF INTEGRATED TRANSPORT SYSTEM OF ENERGY FOR GENERATION PLANNING}

\section{A. Framework of Integrated Transport System Planning Methods}

Integrated transport system refers to an integrity that can effectively meet demand and has structural optimization, integrated transferring and efficiency by a variety of transport modes according to the development ways of comparative advantages and combined function [6]. It is mainly composed of infrastructure, technical equipment and transport services [7], and the scope of this paper is focused on infrastructure. According to planning theory [8], planning and planning evaluation are inseparable; planning in integrated transport 
system surrounds transportation demand forecast to expand discussion, and combined with structure rationality, as well as social benefits evaluation. Transportation demand forecast theory usually utilizes four-stage prediction method based on a collective behavioral models, including transportation generation, transportation distribution, division of transportation ways and transportation pattern construction [9], [10], among which, transportation generation is to forecast transportation volume or transportation demand [11]; transportation distribution forecasts path of transportation flow, division of transportation ways is to forecast all kinds of transportation way proportions according to technical and economic conditions, and transportation pattern construction ultimately forms the network of various transport modes.

\section{B. Differences and Similarities on Top Design of Integrated Transport System of Energy for Generation and Integrated Transport System}

In accordance with the connotation of energy integrated transport system [12], integrated transport system of energy for generation is a generic item consistent with national economic and geographic characteristics and energy resource endowment and productivity development layout and with achieving safe, economic, clean and efficient generating energy system as the goal. In the system, various energy transport ways have their own division of labor, complementary advantages and connected integration. It is made up of the railways, highways, waterways, pipelines, transmission lines and other modes of transport and station, etc, which are optimized and rational. Compared with its integrated transport system planning, integrated transport system of energy for generation also needs to answer the needs of regional transportation demand, transport distribution, transportation mode division and transportation pattern construction; in terms of differences, the latter one also needs to answer category of the transport object, and this issue is not independent of the aforementioned four issues, but influence each other. Firstly, it is because on the premise of satisfying the power generation volume, there is substitutability among various categories of generating energies; secondly is that energy carriers change through energy conversion, and then influence the choice of mode of transport, for example, whether coal in converted into coal power in the place of production, there are many ways of sending to the receiving end like transmission modes and railway transportation.

\section{Planning Methods Framework of Integrated Transport System of Energy for Generation}

On the basis of analysis of top design similarities and differences between integrated transport system and integrated transport system of energy for generation, planning methods framework of integrated transport system of energy for generation is built. The framework involves five modules which is shown in Fig. 1. The first one is transport demand forecast; the second is comparison among modes of transport; the third is transportation pattern construction; the fourth is evaluation of social benefits; the fifth is transport coordination evaluation, among which module one to three involve planning and analysis, module four and five belong to planning evaluation. This module division is based on that the category of transport objects also needs to be planned. It is not similar to the integrated transport system planning, which can be divided into independent transport distribution and transport mode division, but these two are merged into transport pattern construction, and before that only carry out transport mode comparison as the boundary condition.

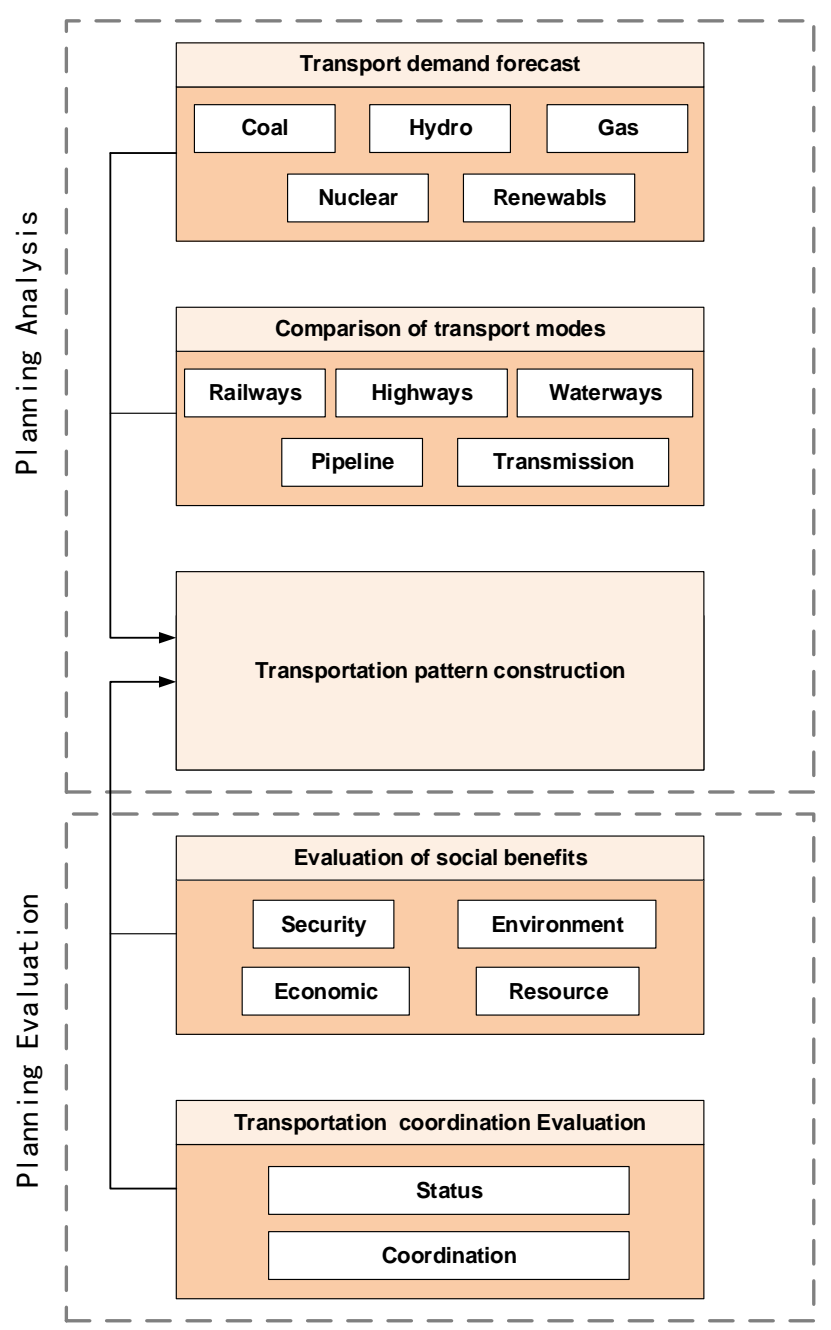

Fig. 1. Planning method framework of integrated transport system of energy for generation

\section{TRANSPORTATION DEMAND FORECAST}

In the transportation demand forecast module, transportation demand of each type of energy for generation and electricity, such as coal, natural gas, hydro, nuclear, wind and solar etc., are forecasted

Forecasting regional transportation demand of energy and electricity is mainly through prediction of the regional demand and supply, and is carried out in accordance with their difference. Lin Boqiang [13] thinks that the energy demand forecast primarily takes into consideration of the impact of economic growth, industrial structure and technological advances; energy supply prediction mainly consider the impact of energy existence, technological advances, and production and construction and other factors. Generating energy demand forecast mainly utilizes conventional methods [14], including time series, regression analysis, input-output method and system dynamics method. 
In terms of generating energy supply forecast, in addition to conventional forecasting methods, energy production growth curve model is also taken [15]. Regional transportation demand can also be carried out directly with common forecasting method, without separating production and consumption.

In terms of final conversion to electricity, there is certain substitutability between different types of energy for generation, energy substitution forecast directly impact transportation demand forecast, but currently related studies are relatively less. Sun Peng, [16] by establishing a dynamic game model, explores the relationships on time, rate with energy differences, technology accumulation efficiency and energy storage constraints when renewable energies substitutes non-renewable energies. Zhang Lifeng [14] uses beyond logarithm production function to study the substitution elasticity among coal, oil and natural gas.

\section{COMPARISON OF TRANSPORT MODES}

In the comparison of transport modes module, for a certain transportation route and type of energy for generation and electricity, advantage comparison of railways, highways, waterways, pipelines, power transmission and other energy transport ways is carried out. This forms reference for transportation pattern construction.

Most studies are focused on the economic comparison of coal and power transmission [17]-[19], in which Wang Yaohua [17] analyzes economics of coal transportation and power transmission from 7 coal production regions to 13 receiving regions nationwide, by comparing electricity consumption prices of each transportation modes. Wang Jian [19] determines the critical power transmission distance outside Xinjiang region from the perspective of social costs. With the increase of concern over social and environmental impacts caused by energy development, on the basis of economic comparison, the number of researches carrying out a combination of qualitative and quantitative comprehensive comparison is gradually increasing. Report [20], using the analytic hierarchy process (AHP), makes a comprehensive comparison on economy, environmental protection, energy efficiency, land cover, disaster and other aspects of coal and power transmission. Zhang Lu [21], using the AHP and fuzzy comprehensive evaluation method, makes a comprehensive comparison on social, economic, environmental, technology and other areas based on oil and gas pipelines and water transport of Pinghu oil and gas field in East China Sea. In addition, there are qualitative researches. Jiang Huiyuan [22] conducts analysis of the impact of the West Inner Mongolia path construction on the Yangtze River coal waterway pattern. Gao Peng [23] makes a comparison between natural gas pipeline network and the electricity network.

\section{TRANSPORTATION PATTERN CONSTRUCTION}

In the transportation pattern construction module, according to the regional transportation demand of determined energy varieties and the alternative energy amount, transportation flow volume and directions are optimized among different regions to maximize the social and environmental benefits, by playing advantages of each transportation mode.

\section{A. Application of Energy Model and Generation Expansion Planning Model}

Multi-region energy models like TIMES are mainly used for tracking environmental footprint, and research application related to energy transport planning has not yet been found in documents. Related generation expansion planning models include WASP (Wien Automatic System Planning Package), P1anElec-Pro (Plan Electricity Pro), OGP (Optimization Generating Planning), Electricity Generation Expansion Analysis System (EGEAS), Model of National Investment (MNI), JASP (Jiaotong Automatic System Planning) and GESP (Generation Electricity System Planning), etc., their fuel price participates in optimization as a given parameter without the effects of transportation, which in turn neglects the integration of electricity and other energy in the production, conversion and transportation.

\section{B. Other Models and Ways}

In addition to the energy model and generation expansion planning model, other models consider the integration of electricity and other energy in the production, conversion and transportation, but researches are restricted on construction of coal and power transmission pattern only. Lin Boqiang [24] comprehensively considers the external costs and the costs of various factors like time, energy loss and investment through fuzzy multi-objective and multi-index transport model and builds the optimal integrated transport pattern in the Northeast, North, Central, East and South China, conducting coal, hydro, etc., transportation in power transmission, railways, roads, shipping and other modes. Zhang Lei [25], by linear programming and taking lowest electricity price as the objective function, analyzes the coal transmission patterns of 30 provinces under constraints of electricity supply capacity, installed capacity and environmental capacity. Zhao Qingbo [26] uses the "big energy concept" to propose multi-regional, multi-resource, multi-dimensional theory of power planning, thus optimizing resource allocation of various resources like energy for generation, water, environment and land.

\section{EVALUATION OF SOCIAL BENEFITS}

In evaluation of social benefits module, assessment on impact of integrated transport system of energy for generation on external systems like economy, society and environment is taken, the aspects mainly include security, GDP promotion, employment and other economic growth, pollutant emissions and effective use of resources and so on.

Social benefits assessment typically utilizes social - energy - economic models such as CGE models, input-output models. etc, or constructs evaluation index system. In terms of security, transportation abundance is usually picked as an indicator [27], [28], in which abundance of various energy modes of transport is evaluated and estimated by experts. Gao Jianbin [29] discusses economic system, political system, diplomatic systems, military systems and natural systems respectively of 41 China's maritime energy transport ways, by building index 
system with normal, emergency and war state. In terms of economic, environmental and resource impacts, Yao Xin [3] conducts quantitative analysis of the impact of increasing power and coal transmission proportion on economic development, energy intensity and emissions like carbon dioxide and sulfur dioxide by CGE model simulation. G. Chen [30], using the input-output model and starting from electricity flow, studies full life-cycle emissions of power transmission and coal transportation. B. Zhang [31] discusses the regional sources and sinks, and studies the implicit energy flow of China's raw coal, oil, gas and other primary energies via input-output model.

\section{EVALUATION OF TRANSPORT COORDINATION}

Transport coordination evaluation module mainly assess development state and mutual coordination level among railways, highways, waterways, pipelines and power transmission and so on, and this area belongs to the internal system evaluation of integrated transport system of energy for generation. The researches in this field are still in the development stage. Jiang Guangjun [32], using data envelopment analysis (DEA), measures the overall efficiency, technical efficiency and scale efficiency of China's coal railway, coal highway, coal waterways, oil and gas pipelines, oil and gas waterways, oil railroad and thermal power transmission and other modes of transport, and proposes future improvement direction of all kinds of energy transport. Jiang Guangjun [33] calculates the information entropy of construction scale of China's railways, highways, waterways and pipeline energy transport ways, and gives a clear construction focus of energy transport channel combined with maximum entropy principle.

\section{OVERSEAS STUDY TRENDS}

In construction of transportation pattern, documents [34] [35] utilize multi-region energy models like TIMES. James Mccalley constructs NETPLAN optimization model framework [36] and can consider optimizing ratio between generating energy resources and cargo supplies. Jose Ignacio [37] further points out that in the widely used energy model MARKAL and TIMES, there is a quantitative defect in dealing with transportation demand of energy for transportation, and compares the results of variables in NETPLAN model. Eduardo Ibáñez builds optimization model on transport of corn, coal, electricity and diesel between the mid-west US and eastern America with minimum cost including emissions as objective function, taking into account the mutual conversion of coal and electricity [38].

In particular, in the optimization of transportation pattern construction, multi-energy transport infrastructure interdependence attracts more attention. These models make use of the Leontief inverse matrix, assessing the failure level of subsystems for the failure of one subsystem from the perspective of resilience, such as internal system consumption decrease [39], supply price change [40], as well as topology changes by external disasters [41] and so on. References [42], [43] assess interdependences from reliability and inoperability. References [44], [45] are focused on how to carry out long-term planning in consideration of highly interdependence among various energy transportation infrastructures. Since Sandy hurricane in the United States in 2012, interdependence studies on energy integrated transport system have attracted more attention due to analysis of disaster resistance [46], [47].

\section{CONCLUSION}

Based on development trends of energy and power, as well as comparison of foreign research, the issues in the coming years to focus on includes, but not limited to:

Firstly, from production to transportation segments, renewable energy, natural gas and other generating energy resources are becoming growingly interdependent, but the current study is mainly focused on integrated planning of power transmission and coal transportation. Planning methods should be further expanded to include wind, solar and other energy resources.

Secondly, in resilience study of energy, China is lagging behind. Considering impact of future high proportion renewable energy on system security, China should carry out a comprehensive study on resilience and inoperability of integrated transport system of energy for generation.

Thirdly, the consideration of power balance. Typically, energy transportation planning is based on the balanced conduct of annual energy supply and consumption, does not need to reach power balance level. However, with the increasing proportion of wind power, solar and other renewable energy, only paying attention to energy balance will lead to ignorance of low capacity factor of new energies, thus affecting the reference value of generating energy transport system planning.

Fourthly, integrated transport system of energy for generation is a complicated system, which contains a large number of uncertainties, such as future energy prices, supply and demand volume, and energy conversion technology costs and efficiency. Current studies usually ignore these uncertainties and may lead to incomprehensive decision results. Future studies may introduce uncertainty optimization theory methods like fuzzy, random and interval planning to enhance the reference value of results.

\section{REFERENCES}

[1] K. Wang, J. Zhan, and Z. Wang, "Models and algorithms for integrated energy transportation system planning," Journal of Dalian University of Technology, no. 3, pp. 103-108, 1985.

[2] D. Yang et al., "Coal transmission problem," Chinese Journal of Management Science, no. 2, 1987.

[3] X. Yao and Q. B. Kong, "China energy comprehensive transport system and its macro influence," Journal of Financial Research, no. 4 pp. 29-39, 2010.

[4] National Development and Reform Commission, "Research on the construction of energy transport channel system," 2010.

[5] B. Mao, "On ideal and strategic design of integrated transport system planning," Journal of Transportation Systems Engineering and Information Technology, no. 3, pp. 1-8, 2014.

[6] R. J. Luo, "Theory and practice of comprehensive transportation system in China," China Communications Press, 2009.

[7] X. P. Xu, "The theory and practice of comprehensive transportation system in China," China Communications Press, 2012. 
[8] Y. H. Yang, Theory, Method and Practice of Development Planning, Tsinghua University press, 2012.

[9] W. Q. Cheng, "Study on optimal allocation of traffic structure and transport resources in transport corridor," Xi'an: Chang'an University, 2011.

[10] H. Peng, "The theory and analysis on comprehensive transportation system,” Xi'an: Chang'an University, 2006.

[11] Q. Q. Wu and $\mathrm{Z}$. Li, "The research frame work of integrated transportation planning based on transportation demand," Journal of Transportation Systems Engineering and Information Technology, no. 1, pp. 13-19, 2011.

[12] Z. Y. Liu, China Power and Energy, China Electric Power Press, 2012

[13] B. Q. Lin, "Structural changes, efficiency improvement and electricity demand forecasting," Economic Research Journal, vol. 93, no. 5, pp. $57-65,2003$

[14] L.-F. Zhang, "The research of the model of energy supply and demand and the development countermeasure of China," Capital University of Economics and Business, Beijing, 2006.

[15] L.-X. Tian and M. Sun, Energy Supply and Demand System Analysis, Science Press, Beijing, 2011.

[16] P. Sun and P.-Y. Nie, "The substitution of renewable energy for depletable energy under dynamic perspective," Systems Engineering, vol. 32, no. 3, pp. 92-98, 2014.

[17] Y.-H. Wang, F.-Y. Zhang, and J.-H. Bai, "Comparative research on the economy of coal transportation and power transmission," Electric Power, vol. 40, no. 12, pp. 6-9, 2007.

[18] R.-B. Shen, L.-Z. Zhang, H. Zhang et al., "Economic comparisons of coal transportation and power transmission," Electric Power, vol. 46, no. 10, pp. 133-139, 2013.

[19] J. Wang, S. Lv, and J. Yang, "Modeling and analyzing for the economy of coal transportation and electricity transmission based on a life cycle method," Chinese Society of Electrical Engineering, 2013.

[20] State Grid Energy Research Institute, "The comprehensive comparison analysis on coal transportation and power transmission," 2013.

[21] L. Zhang, "Our energy comparative study on the mode of transportation-water transport and pipeline transport scheme comparison of oil and gas," Shanghai Maritime University, Shanghai, 2001.

[22] H.-Y. Jiang et al., "Influence of new energy corridor construction in west of Mongolia on coal water transport pattern in Yangtze River area," Railway Transport and Economy, vol. 35, no. 3, pp. 48-53, 2013.

[23] P. Gao et al., "Comparison of natural gas pipeline network and the electric grid and their lessons," International Petroleum Economics, no. 8, pp. 63-67.

[24] B. Q. Lin and X. Yao, "Power industry location optimization and integrative energy transportation system," Economic Research Journal, no. 6, pp. 105-115, 2009.

[25] L. Zhang, X.-Q. Lu, and J. Wang, "Optimization on the structure of coal transportation and electricity transmission in China," Journal of China University of Geosciences (Social Sciences Edition), vol. 14, no. 6, pp. 13-22, 2014

[26] Q. B. Zhao, Z. L. Zhang, and J. H. Bai, "Theory innovation and practice of electric power system planning based on ultra high voltage transmission technology," Proceedings of the CSEE, vol. 34, no. 16, pp. 2523-2532, 2014

[27] M. Ren, L.-F. Wang, and D. Wu, "Energy sustainable development evaluation index system construction and preliminary evaluation in China," Energy of China, vol. 34, no. 3, pp. 22-27, 2012.

[28] J.-Z. Li, "Establishment of Chinese energy early warning model and indicators," Journal of China University of Petroleum (Edition of Natural Science), vol. 31, no. 6, pp. 161-166, 2007.

[29] J. B. Gao, "Research on China's energy marine transportation passage safety evaluation," Dalian Maritime University, Dalian, 2011.

[30] G. Chen, B. Chen, and H. Zhou "Life cycle carbon emission Flow analysis for electricity supply system: A case study of China," Energy Policy, vol. 61, pp. 1276-1284, 2013.

[31] B. Zhang, Z. M. Chen, and X. H. Xia, "The impact of domestic trade on China's regional energy uses: A multi-regional input-output modeling," Energy Policy, vol. 63, pp. 1169-1181, 2013.

[32] G.-J. Jiang, "Research on comprehensive evaluation and optimization of energy transportation corridor in China," China University of Mining and Technology, Beijing, 2011.
[33] G.-J. Jiang and H.-B. Liu, "Theoretical analysis on Information entropy of energy transportation channels in Chin," Journal of Jishou University (Natural Sciences Edition), vol. 32, no. 2, pp. 96-100, 2011.

[34] E. Wright and A. Kanudia, "Low carbon standard and transmission investment analysis in the new multi-region us power sector model facets," Energy Economics, no. 46, pp. 136-150, 2014.

[35] K. Vaillancourt et al., "A Canadian 2050 energy outlook: Analysis with the multi-regional model times-Canada," Applied Energy, vol. 132, pp. 56-65, 2014.

[36] J. Mccalley and E. Ibáñez, Y. Gu, "National long-term investment planning for energy and transportation systems," in Proc. 2010 IEEE Power and Energy Society General Meeting, 2010, pp. 1-7.

[37] J. Ignacio, "A benchmarking approach to net plan using markal/times in analysis of large scale and long-term energy systems," AMES, Iowa: Iowa State University, 2011

[38] E. Ibáñez, K. Gkritza, J. McCalley, D. Aliprantis, R. Brown, A. Somani, and L. Wang, "Interdependencies between energy and transportation systems for national long term planning," in Sustainable \& Resilient Critical Infrastructure Sys., K. Gopalakrishnan and S. Peeta, Eds. Springer-Verlag Berlin Heidelberg, 2010, pp. 53-76.

[39] J. R. Santos and Y. Y. Haimes, "Modeling the demand reduction input-output (I-O) inoperability due to terrorism of interconnected infrastructures," Risk Analysis, vol. 24, no. 6, pp. 1437-51, 2004.

[40] M. Leung and Y. Y. Haimes, "Supply- and output-side extensions to the inoperability input-output model for interdependent infrastructures," Journal of Infrastructure Systems, vol. 13, no. 4, pp. 299-310, 2007.

[41] Y. Okuyama and J. R. Santos, "Disaster impact and input-output analysis," Economic Systems Research, vol. 26, no. 1, pp. 1-12, 2014

[42] D. A. Reed, K. C. Kapur, and R. D. Christie, "Methodology for assessing the resilience of networked infrastructure," Systems Journal, IEEE, vol. 3, no. 2, pp. 174-180, 2009.

[43] T. Brown, W. Beyeler, and D. Barton, "Assessing infrastructure interdependencies: the challenge of risk analysis for complex adaptive systems," International Journal of Critical Infrastructures, vol. 1, no. 1, pp. 108-117, 2004.

[44] K. Gopalakrishnan and S. Peeta, Sustainable \& Resilient Critical Infrastructure System, Springer-Verlag Berlin Heidelberg, pp. 53-76, 2010.

[45] D. D. Dudenhoeffer, M. R. Permann, and M. Manic, "A framework for infrastructure interdependency modeling and analysis," pp. 478-485, 2006.

[46] R. Pant, K. Barker, and C. W. Zobel, "Static and dynamic metrics of economic resilience for interdependent infrastructure and industry sectors," Reliability Engineering \& System Safety, vol. 125, pp. 92-102, 2014

[47] P. Tamvakis and Y. Xenidis, "Comparative evaluation of resilience quantification methods for infrastructure systems," Procedia - Social and Behavioral Sciences, vol. 74, pp. 339-348, 2013.

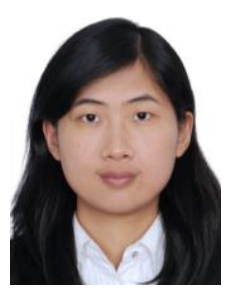

Shengyu Wu was born in Jiangxi Province, China She received her $\mathrm{PhD}$ degree in electrical engineering from Tsinghua University in 2010. Currently, she is with the State Grid Energy Research Institute. Her main research interest is energy and power development strategy and planning.

Bo Yuan was born in Henan Province, China. He received the B.S. degree in mathematics from Nankai University in 2009, and PhD degree in electrical engineering from North China Electric Power University in 2014 respectively. Currently, he is with the State Grid Energy Research Institute. His main research interest is energy and power development strategy and planning.

Songxu Xin was born in Henan Province, China. He received the master degree in electrical engineering from Huazhong University of Science and Technology in 2006. Currently, he is with the State Grid Energy Research Institute. His main research interest is energy and power development strategy and planning. 